\title{
Dual-Task in Large Perceptual Space Reveals Subclinical Hemispatial Neglect
}

\author{
Sanna Villarreal ${ }^{1 * *}$ (D) , Matti Linnavuo ${ }^{2}$, Raimo Sepponen ${ }^{2}$, Outi Vuori ${ }^{1}$, Hanna Jokinen ${ }^{1,3}$ and Marja Hietanen ${ }^{1}$ \\ ${ }^{1}$ Clinical Neurosciences, Neuropsychology, University of Helsinki and Helsinki University Hospital, Helsinki, Finland \\ ${ }^{2}$ Department of Electrical Engineering and Automation, Aalto University, Espoo, Finland \\ ${ }^{3}$ Department of Psychology and Logopedics, Faculty of Medicine, University of Helsinki, Helsinki, Finland
}

(Received October 3, 2019; Final Revision March 3, 2020; Accepted April 14, 2020; First Published Online May 27, 2020)

\begin{abstract}
Objective: Both clinically observable and subclinical hemispatial neglect are related to functional disability. The aim of the present study was to examine whether increasing task complexity improves sensitivity in assessment and whether it enables the identification of subclinical neglect. Method: We developed and compared two computerized dual-tasks, a simpler and a more complex one, and presented them on a large, $173 \times 277 \mathrm{~cm}$ screen. Participants in the study included 40 patients with unilateral stroke in either the left hemisphere (LH patient group, $n=20)$ or the right hemisphere (RH patient group, $n=20$ ) and 20 healthy controls. In addition to the large-screen tasks, all participants underwent a comprehensive neuropsychological assessment. The Bells Test was used as a traditional paper-and-pencil cancellation test to assess neglect. Results: RH patients made significantly more left hemifield omission errors than controls in both large-screen tasks. LH patients' omissions did not differ significantly from those of the controls in either large-screen task. No significant group differences were observed in the Bells Test. All groups' reaction times were significantly slower in the more complex large-screen task compared to the simpler one. The more complex large-screen task also produced significantly slower reactions to stimuli in the left than in the right hemifield in all groups. Conclusions: The present results suggest that dual-tasks presented on a large screen sensitively reveal subclinical neglect in stroke. New, sensitive, and ecologically valid methods are needed to evaluate subclinical neglect.
\end{abstract}

Keywords: Stroke, Unilateral neglect, Divided attention, Computer-based, Neuropsychological assessment, Reaction times

\section{INTRODUCTION}

Hemispatial neglect is a common symptom of right hemisphere stroke (Ringman, Saver, Woolson, Clarke, \& Adams, 2004). Severe neglect becomes clinically observable, for example, in activities of daily living and in neuropsychological screening tests (Gillen, Tennen, \& McKee, 2005; Katz, Hartman-Maeir, Ring, \& Soroker, 1999). Subclinical neglect is more demanding to diagnose but can result in functional disability (Bonato, Priftis, Marenzi, Umiltá, \& Zorzi, 2012; Jehkonen et al., 2000).

Traditional paper-and-pencil tests are not sensitive in revealing subclinical neglect (Bonato \& Deouell, 2013). They have also been criticized for their poor ecological validity since stimuli are static and presented in a narrow visual space (Bonato \& Deouell, 2013; Hasegawa, Hirono, \& Yamadori, 2011; Nakatani, Notoya, Sunahara, Takahashi,

*Correspondence and reprint requests to: Sanna Villarreal, Neuropsychology, Helsinki University Hospital, P. O. Box 302, FI-00029 HUS, Helsinki, Finland. E-mail: sanna.villarreal@helsinki.fi
\& Inoue, 2013; Ulm et al., 2013). There have been various attempts to improve traditional tests' sensitivity. These include, for example, increasing the number or similarity of target and distractor stimuli (Aglioti, Smania, Barbieri, \& Corbetta, 1997; Basagni et al., 2017; Kaplan et al., 1991; Rapcsak, Verfaellie, Fleet, \& Heilman, 1989; Sarri, Greenwood, Kalra, \& Driver, 2009), using time limits in visual searching (Priftis, Di Salvo, \& Zara, 2019), or requiring counting backward while performing the task (Robertson \& Frasca, 1992).

The increased complexity of the test environment enhances assessment sensitivity in revealing neglect (Blini et al., 2016; Bonato, 2012, 2015; Bonato, Priftis, Marenzi, Umiltá, \& Zorzi, 2010; Hasegawa et al., 2011; Robertson \& Manly, 2004). While a large portion of this evidence comes from observations in patients with right hemisphere strokes (Bartolomeo, 2000; Bonato, 2015; Bonato et al., 2012; Bonato, Priftis, Umiltá, \& Zorzi, 2013; Deouell, Sacher, \& Soroker, 2005; Eramudugolla, Boyce, Irvine, \& Mattingley, 2010; Smania et al., 1998; van Kessel, 
van Nes, Geurts, Brouwer, \& Fasotti, 2013), there are also studies showing similar deficits in left hemisphere patients (Blini et al., 2016; Bonato et al., 2010).

New computerized assessment methods requiring divided attention and reacting to dynamic stimuli offer benefits over traditional tests (Bonato et al., 2010; van Kessel, van Nes, Brouwer, Geurts, \& Fasotti, 2010; van Kessel et al., 2013). Variations in task complexity hinder the use of compensatory strategies, and reaction time measurements enhance precision (Bonato \& Deouell, 2013). Traditional tests do not reach similar sensitivity (Deouell et al., 2005; Kim et al., 2010; Tanaka, Sugihara, Nara, Ino, \& Ifukube, 2005; Tsirlin, Dupierrix, Chokron, Coquillart, \& Ohlmann, 2009; Ulm et al., 2013; van Kessel et al., 2010, 2013) even if factors increasing discernment are introduced (Bonato et al., 2012).

Various studies have compared new assessment methods with traditional tests (e.g. Deouell et al., 2005; Kim et al., 2010; Tanaka et al., 2005; Ulm et al., 2013; van Kessel et al., 2010), and computerized dual-tasks with single tasks (Andres et al., 2019; Blini et al., 2016; Bonato, 2015; Bonato et al., 2010, 2012; van Kessel et al. 2013). However, to our knowledge, there is only limited research comparing different computerized dual-tasks. Some of these studies have reported different versions of the dual-task as being sensitive (Blini et al., 2016; Bonato et al., 2010, 2012; Peers, Ludwig, Cusack, \& Duncan, 2006). It has also been shown that low complexity in the primary central task does not reveal neglect in secondary peripheral visual processing, but high complexity does (Vuilleumier \& Driver, 2007). None of these dual-task studies has utilized large screens.

The aim of the present study was to examine whether varying the complexity of the dual-task would improve the sensitivity of the assessment and enable the identification of subclinical neglect. More specifically, we investigated whether a computerized dual-task paradigm and the use of a large perceptual field would yield sufficient complexity in order to differentiate the findings obtained through a traditional paper-and-pencil cancellation test, or whether additional factors increasing task demands would be required. To answer the research problem, we developed and compared two computerized dual tasks: one simpler and the other more complex. The tasks were presented on a $173 \mathrm{~cm} \times 277 \mathrm{~cm}$ screen to enhance ecological validity. The Bells Test was used as a traditional cancellation test to assess neglect. While neglect may occur in different sensory modalities, this study focuses solely on the visual form.

\section{METHOD}

\section{Participants}

A total of 58 potentially eligible consecutive stroke patients receiving rehabilitation at the Neurology Outpatient Clinic of Helsinki University Hospital were selected for recruitment. Recruitment and data collection were carried out between June 2016 and February 2019. The inclusion criteria were native Finnish speakers with first-ever CT (computed tomography) or MRI (magnetic resonance imaging)-verified stroke; no prior neurological diagnosis or bilateral stroke; no visual field defect according to clinical neurological or neuroophthalmological evaluation; no primary impairment in hearing or sight (other than myopia or hyperopia corrected with glasses); no substance abuse; no severe aphasia or other significant cognitive or similar symptom preventing participation; and no severe hemiparesis or other significant motor symptom or psychiatric disease, which would complicate the cooperation. Altogether, 18 patients were excluded because of prior or bilateral stroke, visual field defect, or severe neglect, preventing cooperation. The patients included in the study comprised 20 right hemisphere (RH patient group, 9 men, mean age $53 S D \pm 8$ years) and 20 left hemisphere (LH patient group, 15 men, mean age 51 $S D \pm 9$ years) stroke patients. Fourteen of the RH patients and 10 of the LH patients received multiprofessional neurological outpatient rehabilitation, while the rest of the patients received only neuropsychological outpatient rehabilitation.

Control participants included 20 healthy volunteers (8 men, mean age $46 S D \pm 15$ years) matched with the patient groups in age, gender, and education. The characteristics of the patients and controls are shown in Table 1.

The study protocol was approved by the Ethics Committee of Helsinki University Hospital. All participants gave written informed consent for participation. The data included in the study were obtained in compliance with the Helsinki Declaration.

\section{Procedure}

\section{Comprehensive neuropsychological assessment}

The comprehensive neuropsychological assessment consisted of tests covering multiple cognitive domains. Visual attention was examined with the Bells Test to assess neglect (Gauthier, Dehaut, \& Joanette, 1989). Executive functions and processing speed were examined with the Trail Making Test, parts A and B (Reitan, 1958), the Brixton Spatial Anticipation Test (Burgess \& Shallice, 1997), design, phonetic and semantic fluency (Jones-Gotman \& Milner, 1977; Miller, 1984), and a dual-task modification of the Bourdon-Wiersma Test, including counting numbers backwards and visual dot cancellation (Vilkki, Virtanen, Surma-aho, \& Servo, 1996). Memory was examined with working memory distraction, word list learning, and delayed recall (Christensen, 1979), and with subtests of the Wechsler Memory Scale, third edition (WMS-III): Letter-Number Sequencing and Visual Memory Span (Wechsler, 1997, 2008). Depression was evaluated with the Depression Scale, which consists of 10 items with scores ranging from 0 to 30 (Salokangas, Poutanen, \& Stengard, 1995).

\section{Large-screen tasks}

Apparatus. A new computer-based method, the Active Space, was developed based on near-field imaging technology 
Table 1. Characteristics of the patients and controls

\begin{tabular}{|c|c|c|c|c|c|c|c|}
\hline Demographic and clinical data & LH patients & RH patients & Controls & Statistics & df & $p$ Value & Effect size \\
\hline Age, years ${ }^{\mathrm{a}}$ & $51(9)$ & $53(8)$ & $46(15)$ & $\mathrm{X} 2=2.375$ & 2 & .305 & $\eta^{2}=.007$ \\
\hline Gender, male/female ${ }^{b}$ & $15 / 5$ & $9 / 11$ & $8 / 12$ & $\chi^{2}=5.759$ & 2 & .056 & $V=.310$ \\
\hline Education, years ${ }^{\mathrm{a}}$ & $16(4)$ & $15(3)$ & $16(3)$ & $\mathrm{X} 2=0.390$ & 2 & .823 & $\eta^{2}=-.028$ \\
\hline Depression scale score ${ }^{a}$ & $5(4)$ & $5(4)$ & $3(4)$ & $\mathrm{X} 2=4.158$ & 2 & .125 & $\eta^{2}=.038$ \\
\hline Lesion type, hemorrhage/ischemia/both ${ }^{\mathrm{b}}$ & $1 / 18 / 1$ & $3 / 12 / 5$ & & $\chi^{2}=4.867$ & 2 & .088 & $V=.349$ \\
\hline Days post-onset of stroke prior to study ${ }^{a}$ & $105(42)$ & $106(45)$ & & $U=199.5 ; \mathrm{Z}=-.014$ & 1 & .989 & $r=-.002$ \\
\hline $\begin{array}{l}\text { Neuropsychological out-patient rehabilitation } \\
\text { sessions prior to study }\end{array}$ & $3(2)$ & $3(2)$ & & $U=186.5 ; \mathrm{Z}=-.369$ & 1 & .712 & $r=-.058$ \\
\hline
\end{tabular}

Note. $\mathrm{LH}=$ left hemisphere stroke; $\mathrm{RH}=$ right hemisphere stroke.

${ }^{a}$ Mean $(S D)$, Mann-Whitney $U$ - or Kruskal-Wallis Tests (U/X2).

${ }^{\mathrm{b}}$ Frequency, Pearson Chi-Square Test $\left(\chi^{2}\right)$.

Table 2. Main technical parameters of detection and crash tasks

\begin{tabular}{|c|c|c|}
\hline Technical parameter & Detection task & Crash task \\
\hline Peripheral task paradigm & $\begin{array}{l}\text { Spherical colored flashes in various display } \\
\text { positions. Response with mouse button } 4\end{array}$ & $\begin{array}{l}\text { Spheres cross the display in various directions, randomly } \\
\text { colliding in a flash. Response with mouse button } 4\end{array}$ \\
\hline Target & Red sphere $(\mathrm{RGB}=190,0,0)$ & Two colliding spheres \\
\hline Response window & $250-1000 \mathrm{~ms}$ after target onset & $250-1500 \mathrm{~ms}$ after target onset \\
\hline Sphere diameter & $100 \mathrm{~mm}$ & Moving sphere $90 \mathrm{~mm}$, flash $240 \mathrm{~mm}$ \\
\hline Sphere colors & $\begin{array}{l}\text { Red }(190,0,0) \text {; green }(0,255,0) \text {; blue }(0,0,255) ; \\
\quad \text { cyan }(0,255,255) \text {; yellow }(255,255,0)\end{array}$ & $\begin{array}{l}\text { Moving sphere gray }(127,127,127) \text {, flash white } \\
(255,255,255)\end{array}$ \\
\hline Flash time & $100 \mathrm{~ms}$ & $100 \mathrm{~ms}$ \\
\hline Screen background & Solid gray $(127,127,127)$ & Gray noise \\
\hline Target locations & $\begin{array}{l}10 \text { on left, } 10 \text { on right side of display, random } \\
\text { height and ISI }\end{array}$ & 24 on left, 24 on right, random height and sequence \\
\hline ISI & $1.5 \pm 1.5 \mathrm{~s}$, random & N/A \\
\hline ITI & $6.3 \pm 3.8 \mathrm{~s}$, random & $6.6 \pm 5 \mathrm{~s}$, random \\
\hline Central task paradigm & $\begin{array}{l}\text { Varying numbers in the display center. } \\
\text { Response with mouse button } 4\end{array}$ & $\begin{array}{l}\text { Varying numbers in the display center. Response with } \\
\text { voice burst to lavalier microphone }\end{array}$ \\
\hline Numbers displayed & $0,1,2$, and 3 in random order & $1,2,3,4,5,6,7,8$, and 9 in random sequence \\
\hline Target & Number 2 & A number twice the preceding number \\
\hline Response window & within $1000 \mathrm{~ms}$ after target onset & Within $1500 \mathrm{~ms}$ after target onset \\
\hline Number height & $50 \mathrm{~mm}$ & $245 \mathrm{~mm}$ \\
\hline Display time & $800 \mathrm{~ms}$ & $800 \mathrm{~ms}$ \\
\hline ISI & $1 \mathrm{~s}$ & $1.5 \mathrm{~s}$ \\
\hline ITI & $6,5 \pm 4,5 \mathrm{~s}$, random & $10 \pm 5 \mathrm{~s}$, random \\
\hline
\end{tabular}

Note. $\mathrm{RGB}=$ red, green, blue color space; ISI $=$ interstimulus interval; ITI $=$ intertarget interval.

(Linnavuo, Kovalev, \& Sepponen, 2010; Rimminen, Lindström, Linnavuo, \& Sepponen, 2010). The Active Space includes several means of generating visual stimuli and measuring reaction times. The main visual stimuli generator is a short throw video projector (Epson EB-680, Seiko EPSON Corporation, Suwa, Japan) producing a display of height $173 \mathrm{~cm}$ and a width of $277 \mathrm{~cm}$ on the wall. The midpoint of the screen is located $120 \mathrm{~cm}$ from the floor. The pixel size of the display is $1.9 \mathrm{~mm}$. Control of the Active Space and the task applications are implemented using LabVIEWTM systems engineering software (National Instruments, Austin, TX, USA).
In the research setting, the participant was seated in a chair facing the screen at a $180-\mathrm{cm}$ distance. Thus, the display appeared at an angle of approximately $75^{\circ}$ horizontally and $51^{\circ}$ vertically. The participants performed two distinct dual-tasks. In both, a peripheral visual field task was presented simultaneously with a numeric central task. A short training, including verbal guidance, preceded the actual test session.

Tasks. The main technical parameters of the large-screen tasks are listed in Table 2. 


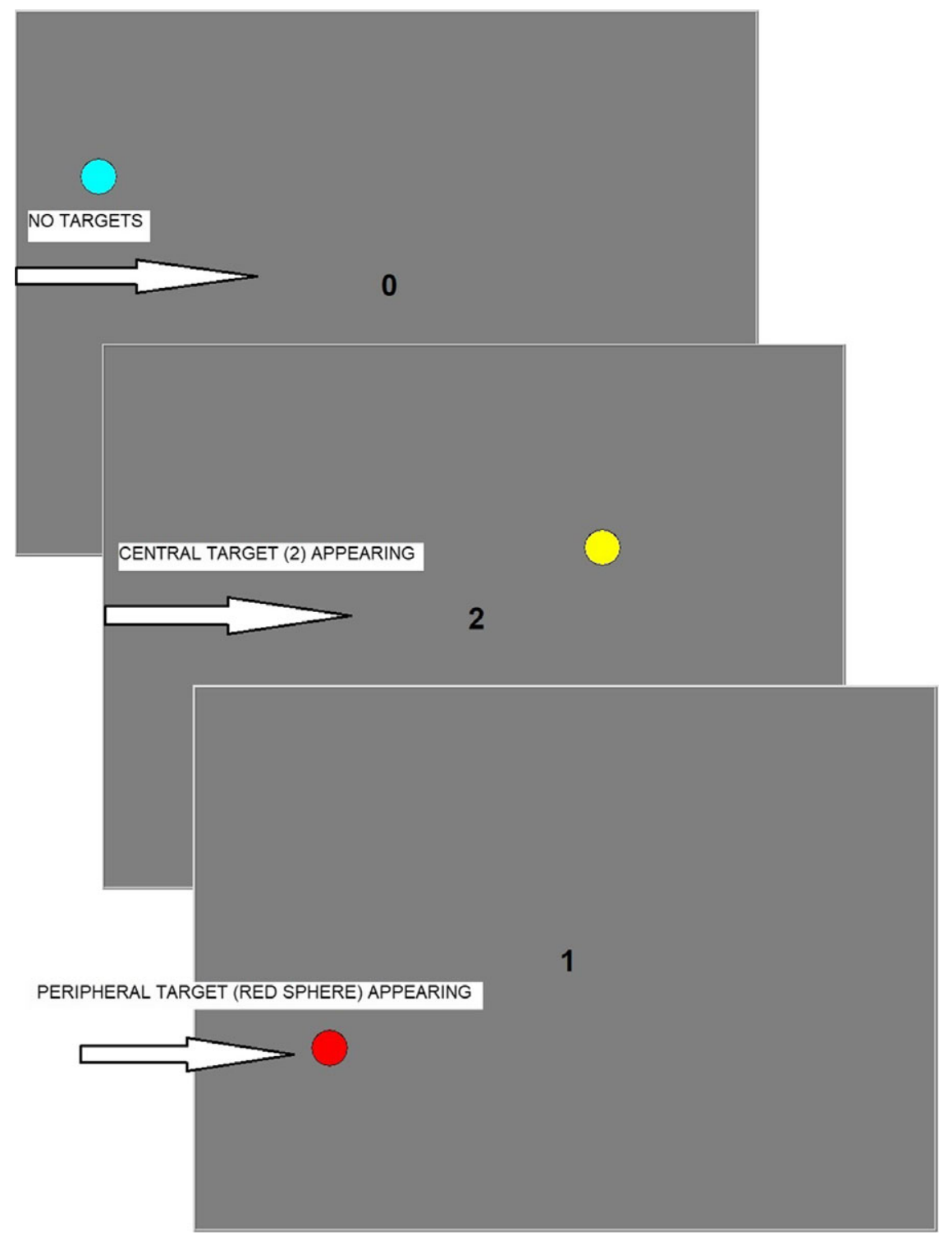

Fig. 1. Visualization of the Detection task. Initially, no targets are visible (top), then a central target appears (middle), and last, a red peripheral target sphere flashes in the left hemifield (bottom).

Detection task. In the peripheral visual field task, the participants were instructed to observe and react to a red sphere flashing among other colored ones, with all spheres appearing one at a time. For the central task, numbers appeared in the center of the screen. Participants were instructed to observe the continuously changing numbers and react only to the number 2. As part of the dual-task paradigm, subjects performed the peripheral visual field task and the central task simultaneously, but peripheral and central targets never appeared at the same time.

The duration of the Detection task was $2 \mathrm{~min}$, and it was preceded by three trial runs of $30 \mathrm{~s}$ : first, both individual tasks were practiced separately, and finally, in the third trial run, the combined dual-task was practiced.

Correct reactions and reaction times, as well as missed stimuli, were extracted. A response was interpreted as "missed" if the participant failed to respond within the allowed temporal window of $1000 \mathrm{~ms}$. If the participant responded before the target appeared or earlier than $250 \mathrm{~ms}$ after target onset, the reactions were excluded as anticipatory errors. Reactions deviating more than $2.5 S D$ from the mean were also excluded as outliers. This was done separately for each participant and condition. A total of $2 \%$ of all reactions were excluded. A visualization of the Detection task is presented in Figure 1.

Crash task. The peripheral visual field task was to observe and react to a collision of two moving gray spheres, resulting in a white flash appearing on the screen. In the central task, numbers appeared at the center of the display. The participants were instructed to follow the continuously changing numbers and react by saying the word "hep" into a lavalier microphone any time a number presented on the screen was exactly twice as high as the immediately preceding figure (alternatives: $1 \rightarrow 2,2 \rightarrow 4,3 \rightarrow 6,4 \rightarrow 8$ ). As part of the dualtask paradigm, subjects performed the peripheral visual field 


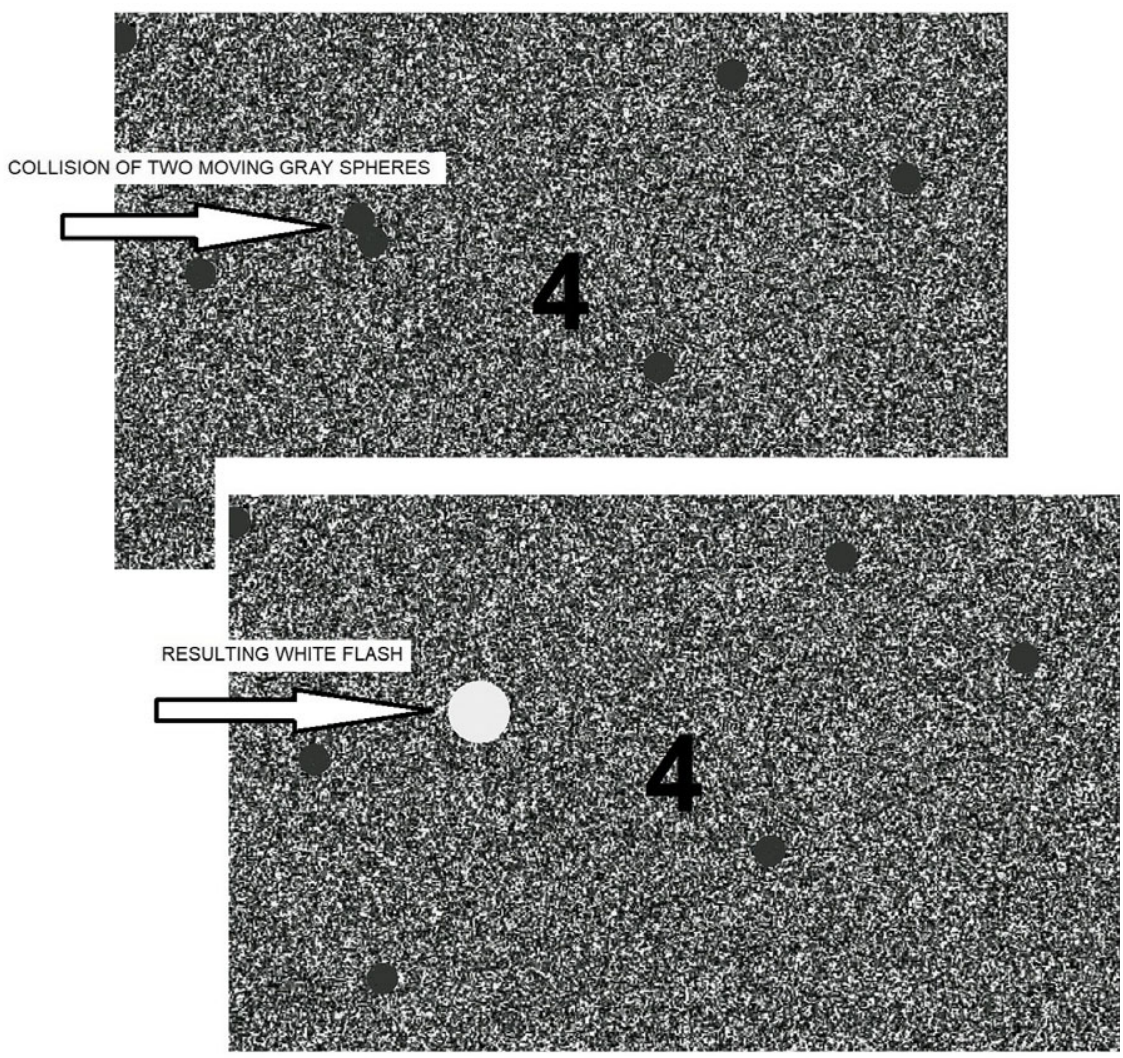

Fig. 2. Visualization of the Crash task. A collision is just happening (top), resulting in a white flash in the left hemifield (bottom).

task and the central task simultaneously, but peripheral and central targets never appeared at the same time.

The duration of the Crash task was 4 min and was preceded by three trial runs of $30 \mathrm{~s}$ : first, both individual tasks were practiced separately, and finally, in the third trial run, the combined dual-task was practiced.

Correct reactions and reaction times, as well as missed stimuli, were extracted. A response was interpreted as "missed" if the participant failed to respond within the allowed temporal window of $1500 \mathrm{~ms}$. If the participant responded before the target appeared, or earlier than $250 \mathrm{~ms}$ after target onset, the reactions were excluded as anticipatory errors. Also, reactions deviating more than 2.5 $S D$ from the mean were excluded as outliers. This was done separately for each participant and condition. A total of 3\% of all reactions were excluded. The visualization of the Crash task is presented in Figure 2.

The Crash task was the more complex of the two dualtasks. Compared to Detection, Crash introduced additional task demands through (1) increased arithmetic demands of the central task, (2) required different reactions in the central and peripheral tasks, (3) doubled the task duration, and (4) decreased the prominence of the targets from the background. All participants performed the Detection task first.

\section{Data Analysis}

The Statistical Package for the Social Sciences (Version 25.0, IBM Corporation, Armonk, NY, USA) was used for statistical analyses. Large-screen task variables were created by calculating the average hit rates and reaction times separately for the left and right peripheral targets. Demographics, clinical and neuropsychological data, and the hit rates of the large-screen tasks were analyzed by using nonparametric methods due to the skewed distribution of the variables. Analyses were performed by using the Mann-Whitney $U$ - or Kruskal-Wallis Tests (U/X2) for continuous variables and the Pearson's Chi-Square Test $\left(\chi^{2}\right)$ for categorical variables. Dunn's Test was used for post hoc analyses. Withingroup analyses (hit rate differences between the two hemifields) were performed using the Wilcoxon Signed-Rank Test. Reaction times were analyzed by using mixed analysis of variance (ANOVA) with Group (RH patients vs. LH patients $v s$. controls) as the between-participants factor and Hemifield (left vs. right) as well as Task (Crash task vs. Detection task) as within-participants factors. For multiple pairwise comparisons, the $p$ values were adjusted using the Bonferroni correction in all post hoc analyses. Effect sizes were calculated by computing eta squared $\left(\eta^{2}\right)$ for the Kruskal-Wallis Test, $r$ for the Mann-Whitney $U$, Wilcoxon Signed-Rank, and Dunn's Tests, Cramer's $V$ for Pearson's Chi-Square Test, and partial eta squared $\left(\eta^{2}\right.$ partial $)$ for mixed ANOVA (Tomczak \& Tomczak, 2014). For significant group differences, Cohen's descriptions for $\eta^{2}$ (partial) (large effect: .14, medium effect: .06, small effect: .01) and for $r$ (large effect: .5, medium effect: .3, small effect: 1 ) were used (Cohen, 1988, pp. 79-80, 283-287, 366-368). The level of statistical significance was set at .05 . 


\section{RESULTS}

\section{Patient and Control Characteristics}

No significant differences were observed between the patient and control groups in demographic or clinical variables (Table 1).

\section{Comprehensive Neuropsychological Assessment}

Statistical analyses of the comparisons between the patients and controls in neuropsychological test scores are shown in Table 3. RH patients were significantly slower than the controls in the Trail Making Test A. Both RH and LH patients performed significantly worse than controls in design fluency. Also, LH patients performed significantly worse than controls in phonetics and RH patients in semantic fluency. Finally, LH patients performed significantly worse than controls in the Bourdon-Wiersma dot cancellation single task and in the dot cancellation and number count dual-tasks. LH and RH patients did not differ significantly on any of the neuropsychological variables.

\section{Large-Screen Tasks}

\section{Hit rates}

Hit rates for the large-screen tasks and statistical comparisons between the participant groups and the two hemifields are shown in Table 4. One right hemisphere stroke patient failed to perform Crash, and therefore, the related analyses are missing one patient (marked with $\bullet$ in Tables 4 and 5).

Detection task. The RH patients missed significantly more targets than the controls in the left hemifield but not in the right hemifield (see Figure 3). The LH patients did not differ significantly from the controls, and no significant differences in hit rates occurred between the patient groups. In the comparison of the two hemifields, the RH patients missed significantly more left hemifield than right hemifield targets (see Figure 3). No significant differences occurred between the two hemifields of the LH patients or the controls.

Crash task. The RH patients missed significantly more left hemifield targets than the controls, but no significant differences occurred in right hemifield targets (see Figure 3). The LH patients and the controls, or the patient groups, did not differ significantly in either hemifield. In the comparison of the two hemifields, the controls missed significantly more right than left hemifield targets (see Figure 3 ). No significant hemifield differences occurred in either patient group.

\section{Reaction times}

Average reaction times and statistical analyses of the betweenand within-participants' effects are shown in Table 5.

There were no significant differences in reaction times for the Detection or Crash targets between RH or LH patients and controls, nor between the patient groups. However, in all groups, within-participants comparisons showed significant task and hemifield $\times$ task effects, with the reaction times for Crash being slower than those for Detection, and for Crash, they were slower over the left than the right hemifield (see Figure 4).

\section{DISCUSSION}

We examined whether varying the complexity of tasks would improve the sensitivity of the assessment and enable the identification of subclinical neglect. We developed and compared two computerized tasks. In both tasks, we used a dual-task paradigm which is reportedly sensitive in detecting neglect (Bonato, 2012; Robertson \& Frasca, 1992; van Kessel et al., 2013). We presented the tasks on a large screen in order to enhance ecological validity (Nakatani et al., 2013; Ulm et al., 2013). Of particular interest was finding whether the demands of the simpler dual-task (Detection) were sufficient to differentiate the findings obtained through the traditional Bells Test, or whether additional demands introduced in the more complex dual-task (Crash) would be required.

The main findings of our study are that both the simpler and more complex large-screen dual-tasks were sensitive in identifying RH patients' subclinical neglect. The RH group missed significantly more left Detection and Crash targets than the control group. The RH group also missed significantly more Detection targets in their left than in their right hemifields. RH patients' neglect did not become evident in the traditional Bells Test. LH patients' performance did not differ from the controls in either of the large-screen tasks or the Bells Test. Task complexity had a general rather than a specifically neglect-revealing effect on reaction times. All groups showed significantly slower reactions for Crash than Detection targets, and they showed prolonged Crash reactions in the left compared to the right hemifields. Both patient groups differed from the controls in several cognitive domains in the comprehensive neuropsychological assessment but did not differ from each other.

The finding that RH patients missed significantly more left targets than the controls in the large-screen tasks but not in the Bells Test was in line with various previous studies comparing new computerized visuospatial and traditional tests (Deouell et al., 2005; Kim et al., 2010; Tanaka et al., 2005; Ulm et al., 2013; van Kessel et al., 2010). Hence, an absence of symptoms in simpler test environments is not necessarily consistent with observations in more complex ones (Blini et al., 2016; Bonato, 2015; Bonato et al., 2010, 2012; Hasegawa et al., 2011). It is possible that the rehabilitation received by the patients may have affected our findings at least to a degree, as early-stage neuropsychological rehabilitation typically utilizes traditional pen-and-paper cancellation tasks. Therefore, the Bells Test may have fallen under a test type familiar to the patients, thereby facilitating the use of compensatory strategies for neglect. It should also be noted that large-screen tasks assess neglect in the 
Table 3. Comprehensive neuropsychological assessment of the patients and controls

\begin{tabular}{|c|c|c|c|c|c|c|c|c|}
\hline Neuropsychological variables ${ }^{a}$ & & $\begin{array}{c}\mathrm{LH} \\
\text { patients }\end{array}$ & $\begin{array}{c}\mathrm{RH} \\
\text { patients }\end{array}$ & Controls & $\begin{array}{l}\text { Statistics } \\
\quad(\mathrm{X} 2)\end{array}$ & df & $\begin{array}{c}p \\
\text { Value }\end{array}$ & $\begin{array}{l}\text { Effect } \\
\text { size }\end{array}$ \\
\hline Bells Test, omissions left & & $1(1)$ & $1(1)$ & $1(1)$ & 3.011 & 2 & .222 & $\overline{\eta^{2}=.018}$ \\
\hline Bells Test, omissions right & & $1(1)$ & $1(1)$ & $0(1)$ & 4.973 & 2 & .083 & $\eta^{2}=.052$ \\
\hline Trail Making Test A, s & & $42(20)$ & $49(23)$ & $29(9)$ & 10.960 & 2 & .004 & $\eta^{2}=.157$ \\
\hline Post hoc comparisons & Mean ranks & 32.23 & 38.65 & 20.62 & & & & \\
\hline Controls versus $\mathrm{RH}$ patients & & & & & 18.025 & & .003 & $r=.52$ \\
\hline LH patients versus RH patients & & & & & 6.425 & & .733 & \\
\hline Controls versus LH patients & & & & & 11.600 & & .107 & \\
\hline Trail Making Test B, s & & $103(62)$ & $94(36)$ & $71(26)$ & 5.252 & 2 & .072 & $\eta^{2}=.057$ \\
\hline Brixton Spatial Anticipation Test, error score & & $14(6)$ & $16(6)$ & $12(4)$ & 4.884 & 2 & .087 & $\eta^{2}=.051$ \\
\hline Phonetic fluency, amount & & $14(6)$ & $17(4)$ & $21(7)$ & 8.317 & 2 & .016 & $\eta^{2}=.111$ \\
\hline Post hoc comparisons & Mean ranks & 22.75 & 30.12 & 38.62 & & & & \\
\hline LH patients versus controls & & & & & -15.875 & & .012 & $r=-.46$ \\
\hline LH patients versus RH patients & & & & & 7.375 & & .542 & \\
\hline RH patients versus controls & & & & & -8.500 & & .369 & \\
\hline Semantic fluency, amount & & $21(8)$ & $21(5)$ & $26(6)$ & 9.300 & 2 & .010 & $\eta^{2}=.128$ \\
\hline Post hoc comparisons & mean ranks & 27.07 & 24.35 & 40.08 & & & & \\
\hline RH patients versus controls & & & & & -15.725 & & .013 & $r=-.45$ \\
\hline RH patients versus LH patients & & & & & -2.725 & & 1.000 & \\
\hline LH patients versus controls & & & & & -13.000 & & .055 & \\
\hline Design fluency, amount & & $8(3)$ & $8(3)$ & $11(4)$ & 13.952 & 2 & .001 & $\eta^{2}=.210$ \\
\hline Post hoc comparisons & Mean ranks & 23.68 & 25.52 & 42.30 & & & & \\
\hline LH patients versus controls & & & & & -18.625 & & .002 & $r=-.54$ \\
\hline RH patients versus controls & & & & & -16.775 & & .007 & $r=-.48$ \\
\hline LH patients versus $\mathrm{RH}$ patients & & & & & 1.850 & & 1.000 & \\
\hline $\begin{array}{l}\text { Bourdon-Wiersma number count (single task), } \\
\text { amount }\end{array}$ & & $43(12)$ & $42(14)$ & $49(15)$ & 1.991 & 2 & .370 & $\eta^{2}=.000$ \\
\hline $\begin{array}{l}\text { Bourdon-Wiersma dot cancellation (single task), } \\
\text { amount }\end{array}$ & & $28(8)$ & $28(8)$ & $34(7)$ & 7.638 & 2 & .022 & $\eta^{2}=.099$ \\
\hline Post hoc comparisons & Mean ranks & 25.88 & 26.32 & 39.30 & & & & \\
\hline LH patients versus controls & & & & & -13.425 & & .045 & $r=-.38$ \\
\hline LH patients versus $\mathrm{RH}$ patients & & & & & .450 & & 1.000 & \\
\hline RH patients versus controls & & & & & -12.975 & & .056 & \\
\hline $\begin{array}{l}\text { Bourdon-Wiersma number count (dual-task), } \\
\text { amount }\end{array}$ & & $23(8)$ & $25(9)$ & $31(11)$ & 6.672 & 2 & .036 & $\eta^{2}=.082$ \\
\hline Post hoc comparisons & mean ranks & 23.85 & 29.62 & 38.02 & & & & \\
\hline LH patients versus controls & & & & & -14.175 & & .031 & $r=-.41$ \\
\hline LH patients versus $\mathrm{RH}$ patients & & & & & 5.775 & & .886 & \\
\hline LH patients versus controls & & & & & -8.400 & & .384 & \\
\hline $\begin{array}{l}\text { Bourdon-Wiersma dot cancellation (dual-task), } \\
\text { amount }\end{array}$ & & $18(7)$ & $20(6)$ & $25(7)$ & 9.424 & 2 & .009 & $\eta^{2}=.130$ \\
\hline Post hoc comparisons & mean ranks & 23.02 & 28.77 & 39.70 & & & & \\
\hline LH patients versus controls & & & & & -16.675 & & .008 & $r=-.38$ \\
\hline LH patients versus $\mathrm{RH}$ patients & & & & & 5.750 & & .892 & \\
\hline RH patients versus controls & & & & & -10.925 & & .143 & \\
\hline Letter-Number Sequencing, score & & $9(3)$ & $9(3)$ & $11(2)$ & 6.434 & 2 & .040 & $\eta^{2}=.078$ \\
\hline Post hoc comparisons & mean ranks & 27.45 & 25.60 & 38.45 & & & & \\
\hline RH patients versus controls & & & & & -12.850 & & .057 & \\
\hline RH patients versus LH patients & & & & & -1.850 & & 1.000 & \\
\hline LH patients versus controls & & & & & -11.000 & & .134 & \\
\hline Visual Memory Span, score & & $15(4)$ & $14(3)$ & $16(4)$ & 4.084 & 2 & .130 & $\eta^{2}=.037$ \\
\hline Verbal working memory distraction, score & & $14(4)$ & $14(3)$ & $16(2)$ & 5.046 & 2 & .080 & $\eta^{2}=.053$ \\
\hline List learning, sum & & $28(6)$ & $32(6)$ & $32(5)$ & 5.082 & 2 & .079 & $\eta^{2}=.054$ \\
\hline Delayed recall, amount & & $7(2)$ & $7(3)$ & $8(2)$ & 4.346 & 2 & .114 & $\eta^{2}=.041$ \\
\hline
\end{tabular}

Note. $\mathrm{LH}=$ left hemisphere stroke; $\mathrm{RH}=$ right hemisphere stroke.

${ }^{a}$ Mean $(S D)$, Kruskal-Wallis Test (X2), mean ranks and post hoc comparisons presented for significant group differences. 
Table 4. Hit rates for the large-screen tasks in the $\mathrm{LH}$ and $\mathrm{RH}$ patients and controls

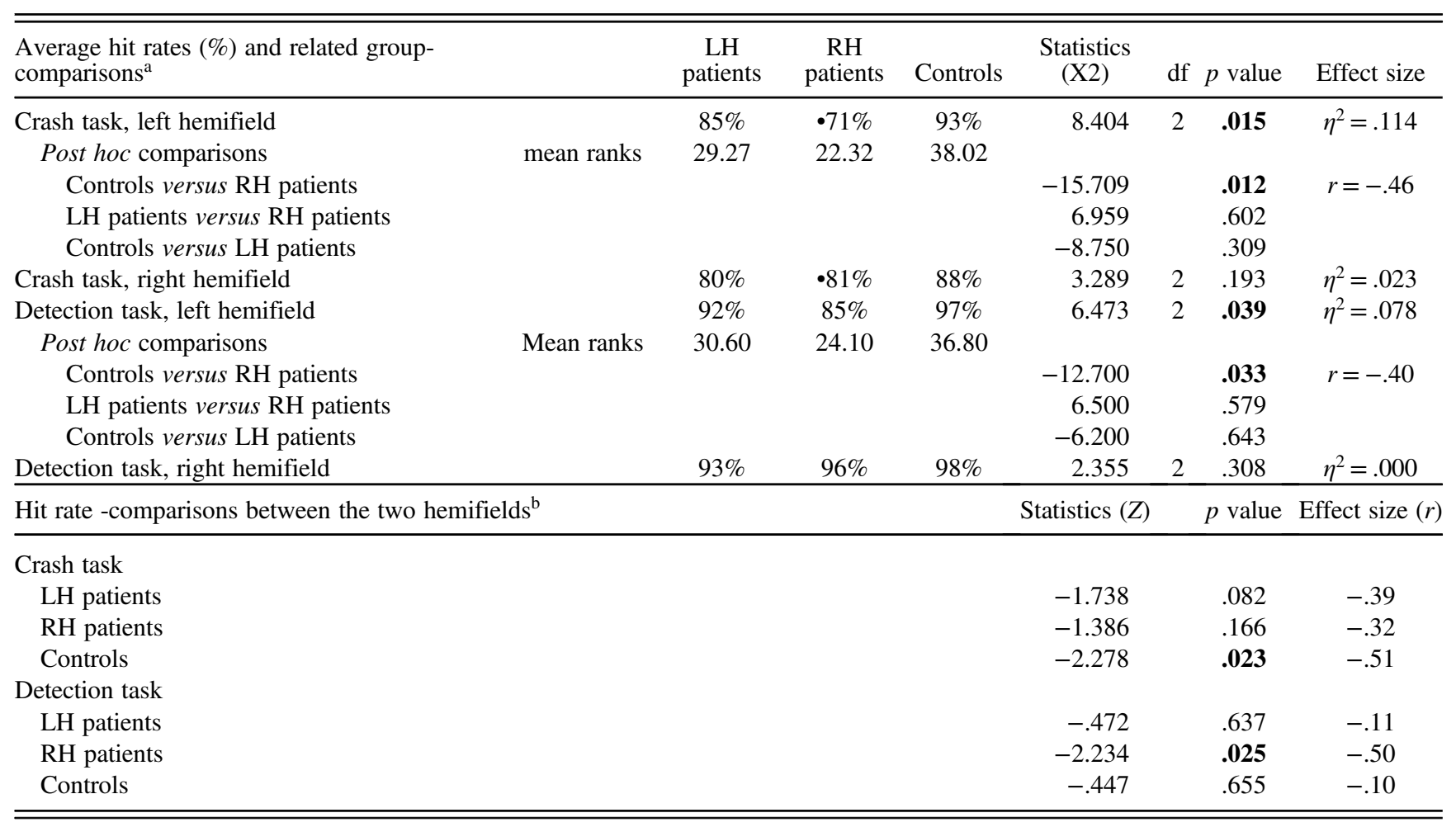

Note. Data for 1 patient missing. $\mathrm{LH}=$ left hemisphere stroke; $\mathrm{RH}=$ right hemisphere stroke.

${ }^{a}$ Kruskall-Wallis Test (X2), mean ranks and post hoc comparisons presented for significant group differences.

${ }^{\mathrm{b}}$ Wilcoxon Signed-Rank Test (Z).

Table 5. Reaction times for the large-screen tasks in the LH and RH patients and controls

\begin{tabular}{|c|c|c|c|c|c|c|c|}
\hline $\begin{array}{l}\text { Average reaction times, ms } \\
\text { (and standard deviations) }^{\mathrm{a}}\end{array}$ & LH patients & RH patients & Controls & Statistics (Wilks $\lambda ; F)$ & df & $p$ value & Effect size $\left(\eta_{\text {partial }}^{2}\right)$ \\
\hline \multicolumn{8}{|l|}{ Crash task } \\
\hline left hemifield & $721(106)$ & •739 (89) & $670(89)$ & & & & \\
\hline right hemifield & $704(84)$ & •708 (101) & $657(93)$ & & & & \\
\hline \multicolumn{8}{|l|}{ Detection task } \\
\hline left hemifield & $508(60)$ & $534(77)$ & $489(55)$ & & & & \\
\hline right hemifield & $525(62)$ & $533(87)$ & $491(52)$ & & & & \\
\hline Between groups -comparisons: & & & & 3.049 & 2 & .055 & .098 \\
\hline \multicolumn{8}{|l|}{ Within-participants' -comparisons: } \\
\hline Hemifield & & & & $.960 ; 2.333$ & 1 & .132 & .040 \\
\hline Hemifield $\times$ Group & & & & $.966 ; 0.986$ & 2 & .379 & .034 \\
\hline Task & & & & $.141 ; 342.371$ & 1 & $<.001$ & .859 \\
\hline Task $\times$ Group & & & & $.982 ; 0.501$ & 2 & .609 & .018 \\
\hline Hemifield $\times$ Task & & & & $.899 ; 6.272$ & 1 & .015 & .101 \\
\hline Hemifield $\times$ Task $\times$ Group & & & & $.991 ; 0.246$ & 2 & .783 & .009 \\
\hline
\end{tabular}

Note. Data for 1 patient missing. $\mathrm{LH}=$ left hemisphere stroke; $\mathrm{RH}=$ right hemisphere stroke.

${ }^{a}$ Repeated-measures-ANOVA.

extrapersonal space while the Bells Test does so in the peripersonal space. Some studies (e.g. Cowey, Small, \& Ellis, 1994; Halligan \& Marshall, 1991) have indicated that these forms of neglect can occur separately from each other. It is, therefore, possible that RH patients in this study suffered from extrapersonal but not peripersonal neglect. However, most previous studies (e.g. Andres et al., 2019; Blini et al., 2016; Bonato, 2015; Bonato et al., 2010, 2012), which have compared more complex computer-based tasks to pen-and-paper methods in the peripersonal space, have found that the computer-based tasks are more sensitive in identifying mild neglect. 


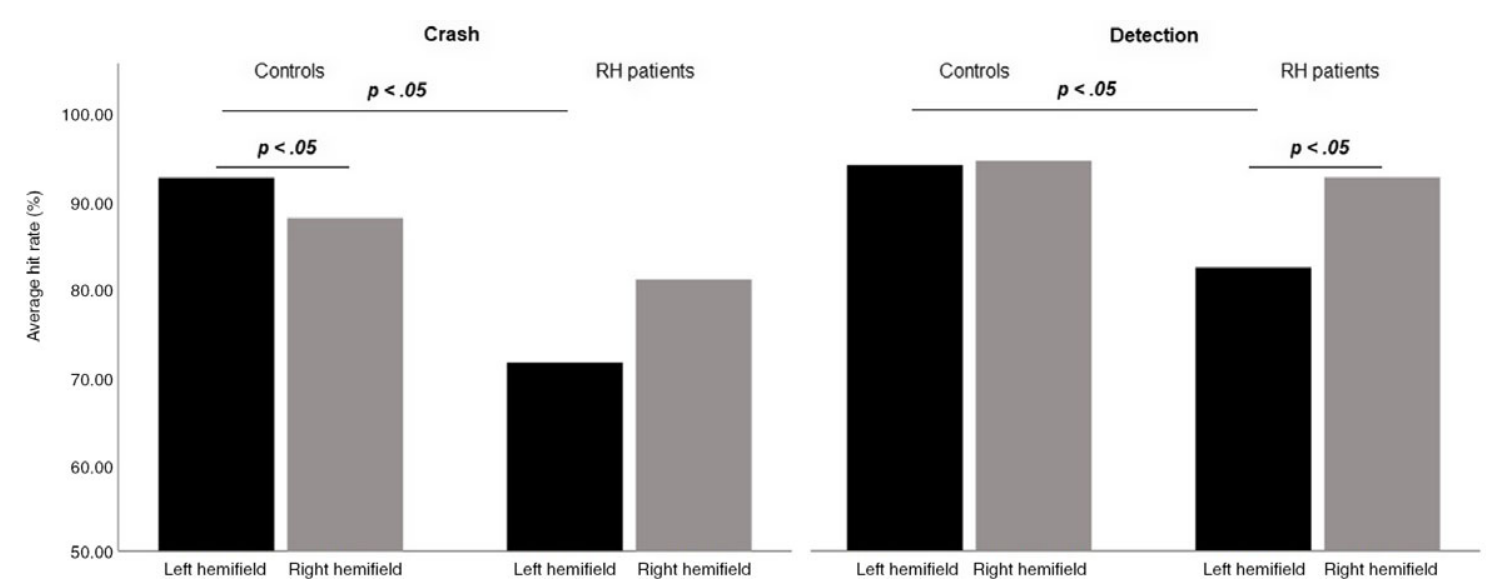

Fig. 3. Average hit rates of the controls and the RH patients in Crash and Detection tasks. In both tasks, RH patients missed significantly more left hemifield targets than controls. Also, RH patients missed significantly more left than right hemifield targets in Detection, and controls missed significantly more right than left hemifield targets in Crash.

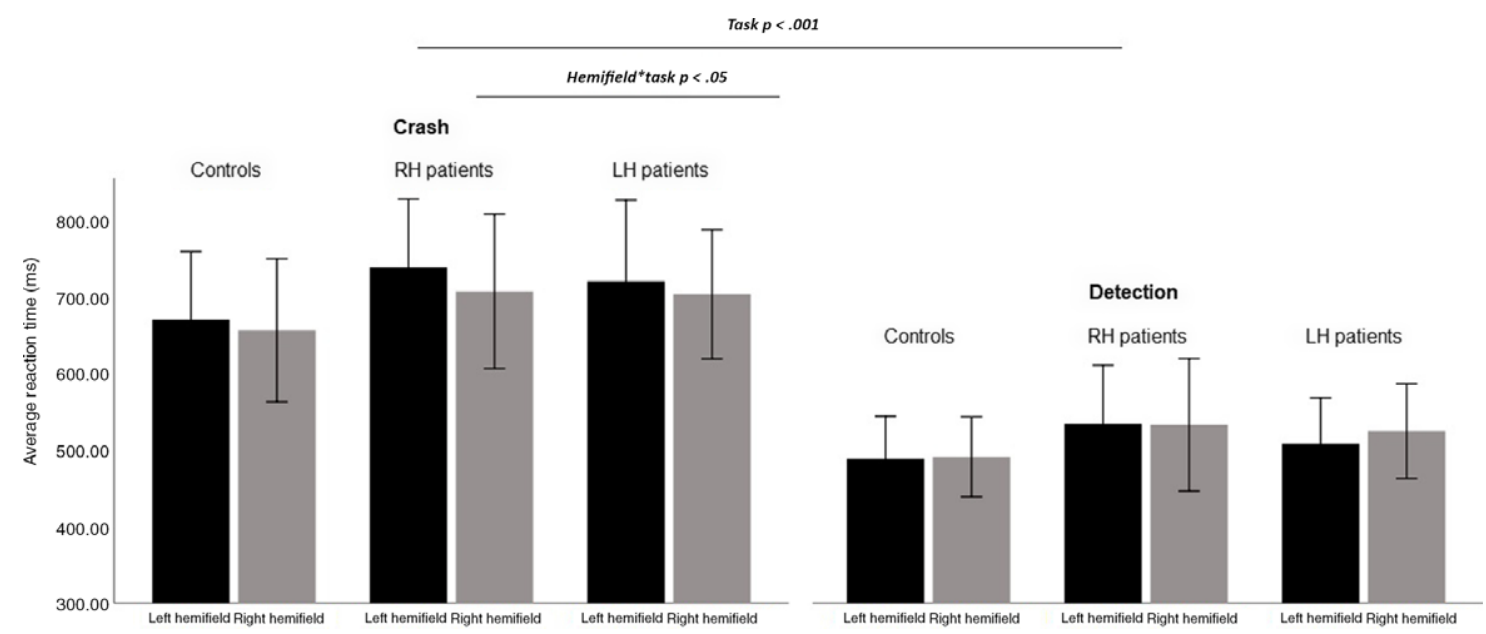

Fig. 4. Average reaction times of the participant groups in Crash and Detection tasks (error bars represent $\pm 1 S D$ ). In all groups, the reaction times for Crash were significantly slower than those for Detection, and for Crash, they were slower over the left than the right hemifield.

Which factors contributed to both large-screen tasks being sensitive in identifying RH patients' subclinical neglect? Traditional tests have been criticized for their poor ecological validity since the stimuli are presented in a narrow visual space (Nakatani et al., 2013; Ulm et al., 2013). Hence, a large test field may be one of the components that increase sensitivity. Further, a dual-task assignment presumably eliminates the typical top-down coping mechanism and brings out symptoms that would otherwise be compensated for (Andres et al., 2019; Bonato, 2015; Robertson \& Frasca, 1992; Robertson \& Manley, 2004; van Kessel et al., 2013). Increases in task demands need not be either visuospatial or attentional in order to improve assessment (Mennemeier, Morris, \& Heilman, 2004; Ricci et al., 2016). For example, arithmetic processing, which was needed in our large-screen central tasks, also enhances task demands to better bring out neglect (Mennemeier et al., 2004; Robertson \& Frasca, 1992). Presumably, simultaneous arithmetic and visuospatial processing introduces deficits in both general and lateralized attention (Ricci et al., 2016). These components interact in neglect, whereby the presence of a general deficit exacerbates the severity of a lateralized one (van Kessel et al., 2010). Successful performance in the large-screen tasks also requires effective executive functions, processing speed, and working memory. These cognitive domains are the ones typically affected after stroke (Farnè et al., 2004; Jaillard, Naegele, Trabucco-Miguel, LeBas, \& Hommel, 2009; Jokinen et al., 2015; Middleton et al., 2014; Nys et al., 2005). Based on the comprehensive neuropsychological assessment, this was also the case with our patients. It may be that these other cognitive deficits exhausted RH patients' attentional resources while performing the large-screen tasks and weakened their ability to compensate for neglect (Smit, Eling, \& Coenen, 2004a; van Kessel et al., 2010). Apparently, sufficient load (i.e. increased task difficulty together with limited processing time) is needed to improve assessment (Priftis et al., 2019).

Although the large-screen tasks differentiated the $\mathrm{RH}$ patients from the controls in terms of left hemifield omissions, there were no group differences in reaction times. This finding 
seems logical considering the fact that the tasks required constant reactions on short interstimulus intervals, and responses were only registered during a short window. Therefore, it may be that longer response times would register more readily as omitted. Supporting the above, some previous studies (Deouell et al., 2005; Rengachary, d'Avossa, Sapir, Shulman, \& Corbetta, 2009) that successfully demonstrate right hemisphere patients' neglect in reaction times have either deliberately chosen a long response window or substituted missed trials with the longest-permitted reaction time. This was done to maximize hits and, hence, improve the signal-to-noise ratio of reaction times. Another essential factor behind the finding might be the fact that controls displayed prolonged Crash reactions for the left as well. This possibly hindered the group difference from becoming noticeable.

In the Crash task, the reactions to the left-side targets were significantly slower than those to the right-side targets. Subject groups did not differ in this respect. As the simpler dual-task, Detection, failed to identify this difference, the increased task complexity possibly influenced the results. This interpretation is supported by the observation of considerably shorter reaction times in Detection than Crash. More demanding tasks could be expected to require more time to process (Bartolomeo, 2000). Crash was not only more demanding from a cognitive perspective, but its duration was also twice that of Detection, and all participants performed Detection first. It may be that the increases in both difficulty and duration, as well as the presentation order, affected the results, possibly through alertness. In fact, several studies have suggested that a decrease in alertness-be it from sleep deprivation, a long test protocol, or high task demands-is associated with a rightward orientation shift. In addition to patients with right hemisphere strokes (Peers et al., 2006; Robertson et al., 1997), similar behaviors have been found with left hemisphere patients (Peers et al., 2006) as well as healthy subjects (Bellgrove, Dockree, Aimola, \& Robertson, 2004; Dobler et al., 2005; Dodds et al., 2008; Fimm, Willmes, \& Spijkers, 2006; Pérez et al., 2009; Takio, Koivisto, Laukka, \& Hämäläinen, 2011; Takio, Koivisto, Tuominen, Laukka, \& Hämäläinen, 2013). This phenomenon has been explained by the domination of right hemispheres in both spatial and sustained attention, as well as their close interconnection (Cavézian et al., 2015; Corbetta, Kincade, Lewis, Snyder, \& Sapir, 2005; He et al., 2007; Posner \& Petersen, 1990; Robertson, 1989, 1993, 2001). It may be that, as proposed by Bellgrove and coworkers (2004), the reduction in sustained attention is associated with decreased activity within the frontoparietal attentional networks underlying both sustained and spatial attention. This decreased activity, then, weakens the right hemisphere spatial attentional systems and drives attention toward the right (Bellgrove et al., 2004). Thus, in the present study, the general rightward bias in Crash reactions might be related to a possible alertness decrement effect as a result of depleted resources in high-complexity tasks (Peers et al., 2006; Smit et al., 2004a; Smit, Eling, \& Coenen, 2004b; Takio, Koivisto, \& Hämäläinen, 2014).
Generalizations from the present interpretations should be made with some caution. The sample size of the study sets certain limitations. Our findings were also inconsistent with some previous studies. There are observations of high task complexity emphasizing right-sided neglect in left hemisphere patients (Blini et al., 2016; Bonato et al., 2010). In our study, conversely, high complexity caused a rightward shift. A possible explanation for this contradiction might be that the LH patients in the present study did not suffer from even subclinical neglect. Hence, the high task complexity would have caused a similar reaction time effect in $\mathrm{LH}$ patients as displayed by healthy controls. Another reason may be that the rightward bias in our study was observed in terms of reaction times, while the abovementioned studies analyzed hit rates. This might explain the contradiction which seems to be supported by healthy controls in our study displaying shorter but more inaccurate reactions toward the right. Supplementary studies are required to clarify this issue. Future studies may also uncover additional information on the effects of task duration on identifying neglect. A longer task would be a more ecologically valid way to assess whether neglect becomes more pronounced through the effects of load and fatigue. Such information would be crucial in a clinical setting, particularly with a view toward a patient's ability to work or operate a vehicle. Future studies should assess the effect of individual factors (i.e. the large perceptual field or the dual-task paradigm) in increasing the overall sensitivity of the method. The present study attempted to increase sensitivity by combining several factors known to increase sensitivity, and because of this, the significance of the individual factors remains elusive. Several previous studies (e.g. Andres et al., 2019; Blini et al., 2016; Bonato, 2015; Bonato et al., 2010, 2012; van Kessel et al. 2013) have already noted that a dual-task paradigm is in itself more sensitive than a single task in bringing out mild neglect. Therefore, the effect of the large visual field would require particular attention in future studies.

To conclude, in this study, we presented a new method for the assessment of visual neglect. We demonstrated that, in a large extrapersonal space, dual-tasks sensitively reveal right hemisphere stroke patients' subclinical neglect. It is important to identify and diagnose all forms of neglect in order to assess the efficacy of rehabilitation and to address specific concerns such as driving ability or working ability in tasks requiring high attention. More sensitive methods than traditional cancellation tests are needed to evaluate these issues. A large test field, together with dynamic stimuli, enhances ecological validity and sensitivity in neglect assessment.

\section{ACKNOWLEDGMENTS}

This work was supported by a grant from the Oskar Öflunds Stiftelse sr. We thank Jari Lipsanen for statistical consultancy, Esko Ruuskanen for his assistance in building the tools for raw data analysis, Viljami Salmela for consultations on visual perception, and Kimmo Alho and Daniel Villarreal for their assistance in proofreading the manuscript. We also 
thank our colleagues who assisted in the recruitment of their patients to the study and the participants who generously gave their time to take part in this research.

\section{CONFLICT OF INTEREST}

The authors have no conflicts of interest to disclose.

\section{REFERENCES}

Aglioti, S., Smania, N., Barbieri, C., \& Corbetta, M. (1997). Influence of stimulus salience and attentional demands on visual search patterns in hemispatial neglect. Brain and Cognition, 34, 388-403. doi: 10.1006/brcg.1997.0915

Andres, M., Geers, L., Marnette, S., Coyette, F., Bonato, M., Priftis, K., \& Masson, N. (2019). Increased cognitive load reveals unilateral neglect and altitudinal extinction in chronic stroke. Journal of the International Neuropsychological Society, 21, 1-10. doi: 10.1017/S1355617719000249

Bartolomeo, P. (2000). Inhibitory processes and compensation for spatial bias after right hemisphere damage. Neuropsychological Rehabilitation, 10, 511-526. doi: 10.1080/09602010050143577

Basagni, B., De Tanti, A., Damora, A., Abbruzzese, L., Varalta, V., Antonucci, G., ... Mancuso, M. (2017). The assessment of hemineglect syndrome with cancellation tasks: A comparison between the Bells Test and the Apples Test. Neurological Sciences, 38, 2171-2176. doi: 10.1007/s10072-017-3139-7

Bellgrove, M.A., Dockree, P.M., Aimola, L., \& Robertson, I.H. (2004). Attenuation of spatial attentional asymmetries with poor sustained attention. NeuroReport, 15, 1065-1069. doi: 10.1097/ 00001756-200404290-00027

Blini, E., Romeo, Z., Spironelli, C., Pitteri, M., Meneghello, F., Bonato, M., \& Zorzi, M. (2016). Multi-tasking uncovers right spatial neglect and extinction in chronic left-hemisphere stroke patients. Neuropsychologia, 92, 147-157. doi: 10.1016/j.neuro psychologia.2016.02.028

Bonato, M. (2012). Neglect and extinction depend greatly on task demands: A review. Frontiers in Human Neuroscience, 6, 195. doi: 10.3389/fnhum.2012.00195

Bonato, M. (2015). Unveiling residual, spontaneous recovery from subtle hemispatial neglect three years after stroke. Frontiers in Human Neuroscience, 9, 413. doi: 10.3389/fnhum.2015.00413

Bonato, M. \& Deouell, L.Y. (2013). Hemispatial neglect: Computerbased testing allows more sensitive quantification of attentional disorders and recovery and might lead to better evaluation of rehabilitation. Frontiers in Human Neuroscience, 7, 162. doi: 10.3389/fnhum.2013.00162

Bonato, M., Priftis, K., Marenzi, R., Umiltá, C., \& Zorzi, M. (2010). Increased attentional demands impair contralesional space awareness following stroke. Neuropsychologia, 48, 3934-3940. doi: 10.1016/j.neuropsychologia.2010.08.022

Bonato, M., Priftis, K., Marenzi, R., Umiltà, C., \& Zorzi, M. (2012). Deficits of contralesional awareness: a case study on what paperand-pencil tests neglect. Journal of Neuropsychology, 26, 20-36. doi: 10.1037/a0025306

Bonato, M., Priftis, K., Umiltá, C., \& Zorzi, M. (2013). Computer-based attention-demanding testing unveils severe neglect in apparently intact patients. Behavioural Neurology, 26, 179-181. doi: 10.3233/BEN-2012-129005
Burgess, P.W. \& Shallice, T. (1997). The Hayling and Brixton Tests. Thurston: Thames Valley Test Company.

Cavézian, C., Perez, C., Peyrin, C., Gaudry, I., Obadia, M., Gout, O., \& Chokron, S. (2015). Hemisphere-dependent ipsilesional deficits in hemianopia: Sightblindness in the "intact" visual field. Cortex, 69, 166-174. doi: 10.1016/j.cortex.2015.05.010

Christensen, A. (1979). Luria's Neuropsychological Investigation (Text, 2nd ed.). Copenhagen: Munksgaard.

Cohen, J. (1988). Statistical Power Analysis for the Behavioral Sciences (2nd ed., pp. 79-80, 283-287, 366-368). New York, NY: Lawrence Erlbaum Associates.

Corbetta, M., Kincade, M.J., Lewis, C., Snyder, A.Z., \& Sapir, A. (2005). Neural basis and recovery of spatial attention deficits in spatial neglect. Nature Neuroscience, 8, 1603-1610. doi: 10. 1038/nn 1574

Cowey, A., Small, M., \& Ellis, S. (1994). Left visuo-spatial neglect can be worse in far than in near space. Neuropsychologia, 32, 1059-1066. doi: 10.1016/0028-3932(94)90152-X

Deouell, L.Y., Sacher, Y., \& Soroker, N. (2005). Assessment of spatial attention after brain damage with a dynamic reaction time test. Journal of the International Neuropsychological Society, 11, 697-707. doi: 10.1017/S1355617705050824

Dobler, V.B., Anker, S., Gilmore, J., Robertson, I.H., Atkinson, J., \& Manly, T. (2005). Asymmetric deterioration of spatial awareness with diminishing levels of alertness in normal children and children with ADHD. Journal of Child Psychology and Psychiatry, 46, 1230-1248. doi: 10.1111/j.1469-7610.2005. 00421.x

Dodds, C.M., van Belle, J., Peers, P.V., Dove, A., Cusack, R., Duncan, J., \& Manly, T. (2008). The effects of time-on-task and concurrent cognitive load on normal visuospatial bias. Journal of Neuropsychology, 22, 545-552. doi: 10.1037/08944105.22.4.545.

Eramudugolla, R., Boyce, A., Irvine, D.R., \& Mattingley, J.B. (2010). Effects of prismatic adaptation on spatial gradients in unilateral neglect: A comparison of visual and auditory target detection with central attentional load. Neuropsychologia, 48, 2681-2692. doi: 10.1016/j.neuropsychologia.2010.05.015

Farnè, A., Buxbaum, L.J., Ferraro, M., Frassinetti, F., Whyte, J., Veramonti, T., ... Làdavas, E. (2004). Patterns of spontaneous recovery of neglect and associated disorders in acute right brain-damaged patients. Journal of Neurology, Neurosurgery and Psychiatry, 75, 1401-1410. doi: 10.1136/jnnp.2002.003095

Fimm, B., Willmes, K., \& Spijkers, W. (2006). The effect of low arousal on visuo-spatial attention. Neuropsychologia, 44, 1261-1268. doi: 10.1016/j.neuropsychologia.2006.01.027

Gauthier, L., Dehaut, F., \& Joanette, Y. (1989). The Bells Test: A quantitative and qualitative test for visual neglect. International Journal of Clinical Neuropsychology, 11, 49-54.

Gillen, R., Tennen, H., \& Mc Kee, T. (2005). Unilateral spatial neglect: Relation to rehabilitation outcomes in patients with right hemisphere stroke. Archives of Physical Medicine and Rehabilitation, 86, 763-767. doi: 10.1016/j.apmr.2004.10.029

Halligan, P.W., \& Marshall, J.C. (1991). Left neglect for near but not far space in man. Nature, 350, 498-500. doi: 10.1038/ $350498 \mathrm{a} 0$

Hasegawa, C., Hirono, N., \& Yamadori, A. (2011). Discrepancy in unilateral spatial neglect between daily living and neuropsychological test situations: A single case study. Neurocase, 17, 518-526. doi: 10.1080/13554794.2010.547506

He, B.J., Snyder, A.Z., Vincent, J.L., Epstein, A., Shulman, G.L., \& Corbetta, M. (2007). Breakdown of functional connectivity 
in frontoparietal networks underlies behavioral deficits in spatial neglect. Neuron, 53, 905-918. doi: 10.1016/j.neuron.2007. 02.013

Jaillard, A., Naegele, B., Trabucco-Miguel, S., LeBas, J.F., \& Hommel, M. (2009). Hidden dysfunctioning in subacute stroke. Stroke, 40, 2473-2479. doi: 10.1161/STROKEAHA.108.541144 Jehkonen, M., Ahonen, J.P., Dastidar, P., Koivisto, A.M., Laippala, P., Vilkki, J., \& Molnár, G. (2000). Visual neglect as a predictor of functional outcome one year after stroke. Acta Neurologica Scandinavica, 101, 195-201. doi: 10.1034/j.16000404.2000.101003195.x

Jokinen, H., Melkas, S., Ylikoski, R., Pohjasvaara, T., Kaste, M., Erkinjuntti, T., \& Hietanen, M. (2015). Post-stroke cognitive impairment is common even after successful clinical recovery. European Journal of Neurology, 22, 1288-1294. doi: 10.1111/ ene. 12743

Jones-Gotman, M. \& Milner, B. (1977). Design fluency: The in vention of nonsense drawings after focal cortical lesions. Neuropsychologia, 15, 653-674. doi: 10.1016/0028-3932(77) 90070-7

Kaplan, R.F., Verfaellie, M., Meadows, M.E., Caplan, L.R., Pessin, M.S., \& DeWitt, L.D. (1991). Changing attentional demands in left hemispatial neglect. Archives of Neurology, 48, 1263-1266. doi: 10.1001/archneur.1991.00530240067023

Katz, N., Hartman-Maeir, A., Ring, H., \& Soroker, N. (1999). Functional disability and rehabilitation outcome in right hemisphere damaged patients with and without unilateral spatial neglect. Archives of Physical Medicine and Rehabilitation, 80, 379-384. doi: 10.1016/s0003-9993(99)90273-3

Kim, D.Y., Ku, J., Chang, W.H., Park, T.H., Lim, J.Y., Han, K., . . . Kim, S.I. (2010). Assessment of post-stroke extrapersonal neglect using a three-dimensional immersive virtual street crossing program. Acta Neurologica Scandinavica, 121, 171-177. doi: 10.1111/j.1600-0404.2009.01194.x

Linnavuo, M., Kovalev, O., \& Sepponen, R. (2010, December). Proactive Space - A Novel Post Stroke Mobility Rehabilitation Tool. 2nd Circuits and Systems for Medical and Environmental Applications, Merida, Mexico.

Mennemeier, M.S., Morris, M., \& Heilman, K.M. (2004). Just thinking about targets can aggravate neglect on cancellation tests. Neurocase, 10, 29-38. doi: 10.1080/13554790490960468

Middleton, L.E., Lam, B., Fahmi, H., Black, S.E., McIlroy, W.E., Stuss, D.T., ... Turner, G.R. (2014). Frequency of domainspecific cognitive impairment in sub-acute and chronic stroke. NeuroRehabilitation, 34, 305-312. doi: 10.3233/NRE-131030

Miller, E. (1984). Verbal fluency as a function of a measure of verbal intelligence and in relation to different types of cerebral pathology. British Journal of Clinical Psychology, 23, 53-57.

Nakatani, K., Notoya, M., Sunahara, N., Takahashi, S., \& Inoue, K. (2013). Horizontal visual search in a large field by patients with unilateral spatial neglect. Journal of Clinical Neuroscience, 20, 837-841. doi: 10.1016/j.jocn.2012.07.014

Nys, G.M., van Zandvoort, M.J., de Kort, P.L., van der Worp, H.B., Jansen, B.P., Algra, A., . . Kappelle, L.J. (2005). The prognostic value of domain-specific cognitive abilities in acute first-ever stroke. Neurology, 64, 821-827. doi: 10.1212/01.WNL.000015 2984.28420.5A

Peers, P.V., Ludwig, C.J.H., Cusack, R., \& Duncan, J. (2006). Modulation of spatial bias in the dual task paradigm: Evidence from patients with unilateral parietal lesions and controls. Neuropsychologia, 44, 1325-1335. doi: 10.1016/j.neuro psychologia.2006.01.033
Pérez, A., Peers, P.V., Valdés-Sosa, M., Galán, L., García, L., \& Martínez-Montes, E. (2009). Hemispheric modulations of alpha-band power reflect the rightward shift in attention induced by enhanced attentional load. Neuropsychologia, 47, 41-49. doi: 10.1016/j.neuropsychologia.2008.08.017

Posner, M.I., \& Petersen, S.E. (1990). The attention system of the human brain. The Annual Review of Neuroscience, 13, 25-42. doi: 10.1146/annurev.ne.13.030190.000325

Priftis, K., Di Salvo, S., \& Zara, D. (2019). The importance of time limits in detecting signs of left visual peripersonal neglect: a multiple single-case, pilot study. Neurocase, 25, 209-215. doi: 10.1080/13554794.2019.1658788

Rapcsak, S.Z., Verfaellie, M., Fleet, W. S, \& Heilman, K.M. (1989). Selective attention in hemispatial neglect. Archives of Neurology, 46, 178-182. doi: 10.1001/archneur.1989.00520380082018

Rengachary, J., d'Avossa, G., Sapir, A., Shulman, G.L., \& Corbetta, M. (2009). Is the posner reaction time test more accurate than clinical tests in detecting left neglect in acute and chronic stroke? Archives of Physical Medicine and Rehabilitation, 90, 2081-2088. doi: 10.1016/j.apmr.2009.07.014

Reitan, R.M. (1958). Validity of the Trail Making Test as an indicator of organic brain damage. Perceptual and Motor Skills, 8, 271-276. doi: 10.2466/pms.1958.8.3.271

Ricci, R., Salatino, A., Garbarini, F., Ronga, I., Genero, R., Berti, A., \& Neppi-Mòdona, M. (2016). Effects of attentional and cognitive variables on unilateral spatial neglect. Neuropsychologia, 92, 158-166. doi: 10.1016/j.neuropsychologia.2016.05.004

Rimminen, H., Lindström, J., Linnavuo, M., \& Sepponen, R. (2010). Detection of falls among the elderly by a floor sensor using the electric near field. IEEE Transactions on Information Technology in Biomedicine, 14, 1475-1476. doi: 10.1109/TITB. 2010.2051956

Ringman, J.M., Saver, J.L., Woolson, R.F., Clarke, W.R., \& Adams, H.P. (2004). Frequency, risk factors, anatomy, and course of unilateral neglect in an acute stroke cohort. Neurology, 63, 468-474. doi: 10.1212/01.wnl.0000133011.10689.ce

Robertson, I.H. (1989). Anomalies in the laterality of omissions in left unilateral visual field neglect: Implications for an attentional theory of neglect. Neuropsychologia, 27, 157-165. doi: 10.1016/ 0028-3932(89)90168-1

Robertson, I.H. (1993). The relationship between lateralized and non-lateralized attentional deficits in unilateral neglect. In I.H. Robertson, \& J.C. Marshall (Eds.), Unilateral Neglect: Clinical and Experimental Studies (pp. 257-275). Hove: Lawrence Erlbaum Associates.

Robertson, I.H. (2001). Do we need the "lateral" in unilateral neglect? Spatially nonselective attention deficits in unilateral neglect and their implications for rehabilitation. NeuroImage, 14, 85-90. doi: 10.1006/nimg.2001.0838

Robertson, I. \& Frasca, R. (1992). Attentional load and visual neglect. International Journal of Neuroscience, 62, 45-56. doi: 10.3109/00207459108999756

Robertson, I. \& Manly, T. (2004). Cognitive routes to the rehabilitation of unilateral neglect. In H.-O. Karnath, A.D. Milner, \& G. Vallar (Eds.), The Cognitive and Neural Bases of Spatial Neglect (pp. 365-373). New York, NY: Oxford University Press.

Robertson, I.H., Manly, T., Beschin, N., Daini, R., Haeske-Dewick, H., Hömberg, V., .. W Weber, E. (1997). Auditory sustained attention is a marker of unilateral spatial neglect. Neuropsychologia, 35, 1527-1532. doi: 10.1016/s0028-3932(97)00084-5

Salokangas, R.K., Poutanen, O., \& Stengård, E. (1995). Screening for depression in primary care. Development and validation of the 
Depression Scale, a screening instrument for depression. Acta Psychiatrica Scandinavica, 92, 10-16. doi: 10.1111/j.16000447.1995.tb09536.x

Sarri, M., Greenwood, R., Kalra, L., \& Driver, J. (2009). Taskrelated modulation of visual neglect in cancellation tasks. Neuropsychologia, 47, 91-103. doi: 10.1016/j.neuropsychologia. 2008.08.020

Smania, N., Martini, M.C., Gambina, G., Tomelleri, G., Palamara, A., Natale, E., \& Marzi, C.A. (1998). The spatial distribution of visual attention in hemineglect and extinction patients. Brain, 121, 1759-1770. doi: 10.1093/brain/121.9.1759

Smit, A.S., Eling, P.A.T.M., \& Coenen, A.M.L. (2004a). Mental effort causes vigilance decrease due to resource depletion. Acta Psychologica, 115, 35-42. doi: 10.1016/j.actpsy.2003.11.001

Smit, A.S., Eling, P.A.T.M., \& Coenen, A.M.L. (2004b). Mental effort affects vigilance enduringly: After-effects in EEG and behaviour. International Journal of Psychophysiology, 53, 239-243. doi: 10.1016/j.ijpsycho.2004.04.005

Takio, F., Koivisto, M., \& Hämäläinen, H. (2014). The influence of executive functions on spatial biases varies during the lifespan. Developmental Cognitive Neuroscience, 10, 170-180. doi: 10.1016/j.dcn.2014.09.004

Takio, F., Koivisto, M., Laukka, S.J., \& Hämäläinen, H. (2011). Auditory rightward spatial bias varies as a function of age. Developmental Neuropsychology, 36, 367-387. doi: 10.1080/ 87565641.2010 .549984

Takio, F., Koivisto, M., Tuominen, T., Laukka, S.J., \& Hämäläinen, H. (2013). Visual rightward spatial bias varies as a function of age. Laterality, 18, 44-67. doi: 10.1080/13576 50X.2011.628675

Tanaka, T., Sugihara, S., Nara, H., Ino, S., \& Ifukube, T. (2005). A preliminary study of clinical assessment of left unilateral spatial neglect using a head mounted display system (HMD) in rehabilitation engineering technology. Journal of NeuroEngineering and Rehabilitation, 2, 31-40. doi: 10.1186/1743-0003-2-31
Tomczak, M., \& Tomczak, E. (2014). The need to report effect size estimates revisited. An overview of some recommended measures of effect size. Trends in Sport Science, $1,19-25$.

Tsirlin, I., Dupierrix, E., Chokron, S., Coquillart, S., \& Ohlmann, T. (2009). Uses of virtual reality for diagnosis, rehabilitation and study of unilateral spatial neglect: Review and analysis. CyberPsychology \& Behavior, 12, 175-181. doi: 10.1089/cpb. 2008.0208

Ulm, L., Wohlrapp, D., Meinzer, M., Steinicke, R., Schatz, A., Denzler, P., ... Winter, Y. (2013). A circle-monitor for computerised assessment of visual neglect in peripersonal space. PLoS One, 8, e82892. doi: 10.1371/journal.pone.0082892

van Kessel, M.E., van Nes, I.J., Brouwer, W.H., Geurts, A.C., \& Fasotti, L. (2010). Visuospatial asymmetry and non-spatial attention in subacute stroke patients with and without neglect. Cortex, 46, 602-612. doi: 10.1016/j.cortex. 2009.06.004

van Kessel, M.E., van Nes, I.J., Geurts, A.C., Brouwer, W.H., \& Fasotti, L. (2013). Visuospatial asymmetry in dual-task performance after subacute stroke. Journal of Neuropsychology, 7, 72-90. doi: 10.1111/j.1748-6653.2012.02036.x

Vuilleumier, P. \& Driver, J. (2007). Modulation of visual processing by attention and emotion: windows on causal interactions between human brain regions. Philosophical transactions of the Royal Society of London, Series B, Biological sciences, 362, 837-855. doi: 10.1098/rstb.2007.2092

Vilkki, J., Virtanen, S., Surma-aho, O., \& Servo, A. (1996). Dual task performance after focal cerebral lesions and closed head injuries. Neuropsychologia, 11, 1051-1056. doi: 10.1016/00283932(96)00028-0

Wechsler, D. (1997). Wechsler Memory Scale - Third Edition (WMS-III). San Antonio, TX: The Psychological Corporation.

Wechsler, D. (2008). WMS-III Käsikirja. [The WMS-III. A Finnish Manual]. Helsinki: Psykologien Kustannus Oy. 